\title{
Review
}

\section{Transcriptional networks controlling pancreatic development and beta cell function}

\author{
J. M. Servitja ${ }^{1}$ J. Ferrer ${ }^{1}$ \\ ${ }^{1}$ Endocrinology, Hospital Clínic de Barcelona, Institut d'Investigacions Biomèdiques August Pi i Sunyer, Barcelona, Spain
}

\begin{abstract}
Transcription factors provide the genetic instructions that drive pancreatic development and enable mature beta cells to function properly. To understand fully how this is accomplished, it is necessary to unravel the regulatory networks formed by transcription factors acting on their genomic targets. This article discusses recent advances in our understanding of how transcriptional networks control early pancreas organogenesis, embryonic endocrine cell formation and the differentiated function of adult beta cells. We discuss how mutations in several transcription factor
\end{abstract}

genes involved in such networks cause Maturity onset diabetes of the young (MODY). Finally, we propose that pancreatic gene programs might be manipulated to generate beta cells or to enhance the function of existing beta cells, thereby providing a possible treatment of different forms of diabetes.

Keywords Chromatin immunoprecipitation . Gene networks · Haplo-insufficiency $\cdot \operatorname{Hnf} 1 \alpha$. Hnf $1 \beta \cdot \operatorname{Hnf} 4 \alpha \cdot$ Islets of Langerhans - MODY1 . MODY3 $\cdot \mathrm{Ngn} 3 \cdot \mathrm{Nkx} 2.2 \cdot \mathrm{Pdx} 1 \cdot$ Stem cells $\cdot$ Type 1 diabetes mellitus - Type 2 diabetes mellitus

\section{Introduction}

Transcription factors control the ability of stem cells to maintain their undifferentiated state $[1,2]$. They also control the developmental process that leads to the formation of beta cells [3], and provide the genetic program for adult beta cells to function properly $[4,5$,

Received: 4 November 2003 / Accepted: 6 February 2004

Published online: 1 April 2004

(C) Springer-Verlag 2004

\section{J. Ferrer (}

Endocrinology, Hospital Clínic de Barcelona,

Institut d'Investigacions Biomèdiques August Pi i Sunyer,

Villarroel 170, Barcelona-08036, Spain

E-mail: jferrer@medicina.ub.es

Tel.: +34-2275400-3028, Fax: +34-934516638

Abbreviations: ChIP, chromatin immunoprecipitation .

E, embryonic day $\cdot$ Hnf, hepatocyte nuclear factor $\cdot$ Lrh1, liver receptor homologue 1 - MODY, Maturity onset diabetes of the young $\cdot$ Ngn3, neurogenin $3 \cdot$ Pklr, L-pyruvate kinase
$6,7]$. It was originally thought that single dedicated transcriptional activators might be responsible for directing the specific phenotype of each cell type. The accumulated evidence points instead to a combinatorial mode of action, whereby unique sets of transcription factors determine the identity and function of a cell. For a set of transcription factors to be expressed in a specific cell, mechanisms need to be in place to initiate and maintain the transcription of their genes. This is achieved through networks formed by transcription factors that directly regulate the promoters of genes encoding other transcription factors [8, 9]. Thus, each cell type possesses not only a unique combination of transcription factors, but also a specific gene regulatory network structure.

With the advent of the sequences of entire genomes of key model organisms and the technologies to analyse them, we can realistically expect to obtain most of the relevant experimental information pertaining to pancreatic transcription networks. Deciphering the logic of such networks is highly relevant to the pathophysiology and treatment of diabetes. Knowledge of 


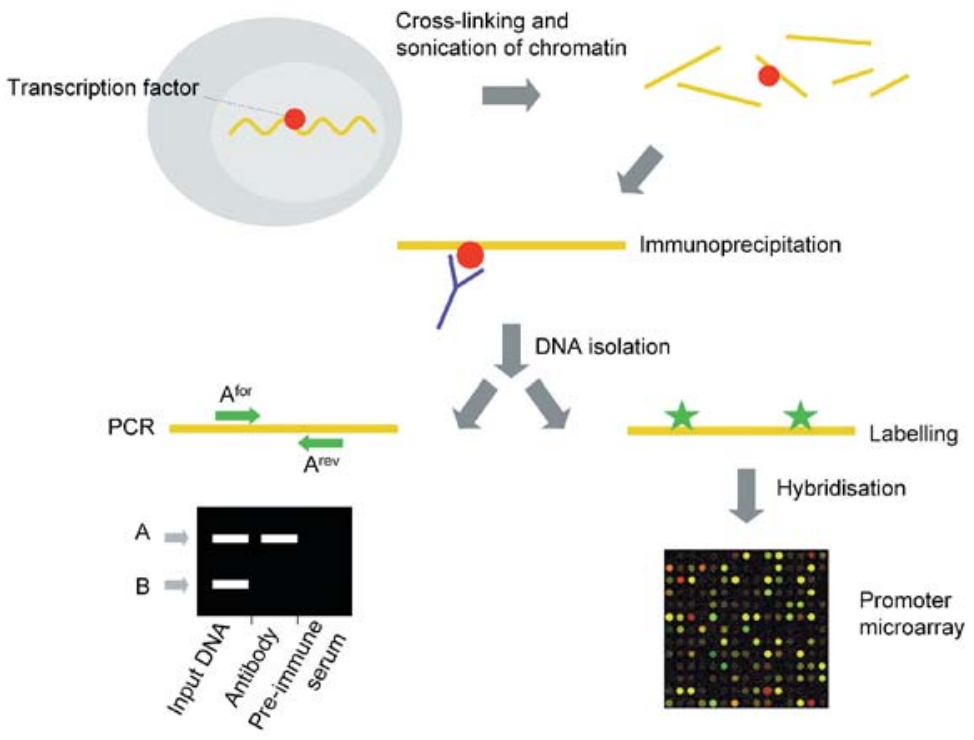

Fig. 1. Analysis of transcription factor promoter interactions using the chromatin immunoprecipitation (ChIP) assay. The ChIP assay can show that a native transcription factor binds to an endogenous gene in a specific cell type [15]. Living cells are exposed to formaldehyde to crosslink proteins bound to DNA. The cells are lysed, chromatin is sheared by sonication, and an antibody against a DNA-binding protein is used to immunoprecipitate the chromatin fragments to which the protein is bound. After DNA purification, specific DNA segments are assayed for enrichment in the immunoprecipitate. This is achieved by PCR amplification of the candidate target gene segment and a negative control DNA, which is not expected to be enriched ( $\mathrm{A}$ and $\mathrm{B}$ respectively). The amplification pattern is compared with that obtained in unenriched ("input") genomic DNA [167]. Alternatively, ChIP-enriched DNA can be hybridised to microarrays containing a large number of promoter or intergenic fragments, a technique known as ChIP-on-chip $[168,169]$. $\mathrm{A}^{\text {for }}$, A forward; $\mathrm{A}^{\text {rev }}$, A reverse oligonucleotide primer

pancreatic gene programs could enable in vitro recapitulation of embryonic development to produce functioning insulin-producing cells. It could also enable in vivo stimulation of beta cell regeneration for the treatment of Type 1 diabetes $[10,11,12]$. In addition it could help us to understand the pathophysiology of monogenic forms of diabetes caused by mutations in genes encoding transcription factors [7, 13, 14]. An in-depth understanding of beta cell transcription programs could also help in the development of drugs to treat insulin secretory dysfunction in Type 2 diabetes.

In this article we discuss the process of pancreatic development and beta cell differentiation from the perspective of its transcriptional control. Particular focus is placed on emerging evidence revealing the in vivo structure of transcription networks within distinct cells of the developing and adult pancreas, and on providing insights into how such knowledge can affect our understanding of pancreatic gene regulation.

\section{Interpreting experimental data on transcription networks}

The information currently available on pancreatic gene networks is still very incomplete. As this information increases, so will its apparent complexity. To interpret the functional logic of such large networks, it will ultimately be crucial not only to obtain sufficient experimental data, but also to define the significance and level of certainty for each of the network components.

A major source of information on transcription networks is studies using mice with targeted inactivation of a transcription factor gene. Using either microarrays or more focused analysis of candidates, such knock-out models can identify which genes are activated or repressed by a transcription factor of interest in specific tissues and developmental stages. Yet these studies do not distinguish between direct and indirect effects. The inactivation of a transcription factor in an animal can modify the function of a cell and of the entire organism, and this can exert profound changes in the expression of genes that are not directly bound by the transcription regulator. Thus, to understand the structure of a gene network, we need to complement differential expression data with biochemical evidence indicating which effects reflect direct regulation.

Traditionally the analysis of direct interactions between transcription factors and promoters has been carried out through in vitro binding assays and transient transfection studies in cultured cell lines. Such studies can be invaluable for detailed mechanistic analysis of promoters. However, they do not prove that an interaction occurs at physiological concentrations of the factor in the native chromatin environment of the target gene. Moreover, they cannot address in which cells the interaction occurs in vivo. In this respect, chromatin immunoprecipitation (ChIP) has emerged as a method for demonstrating that a transcription factor binds to a gene segment in a specific cell type (Fig. 1) [15]. Other useful in vivo tools are 
E9-E10

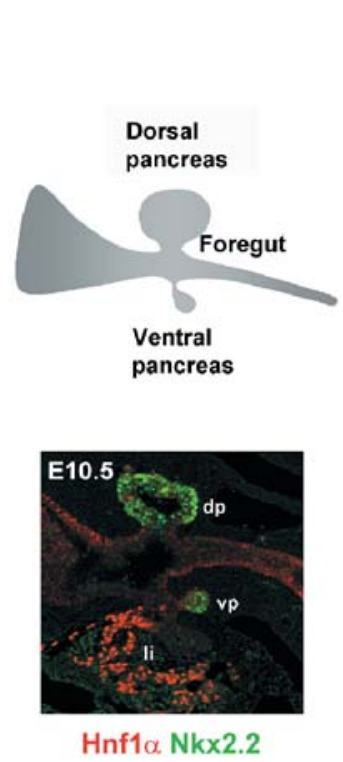

E14-E17

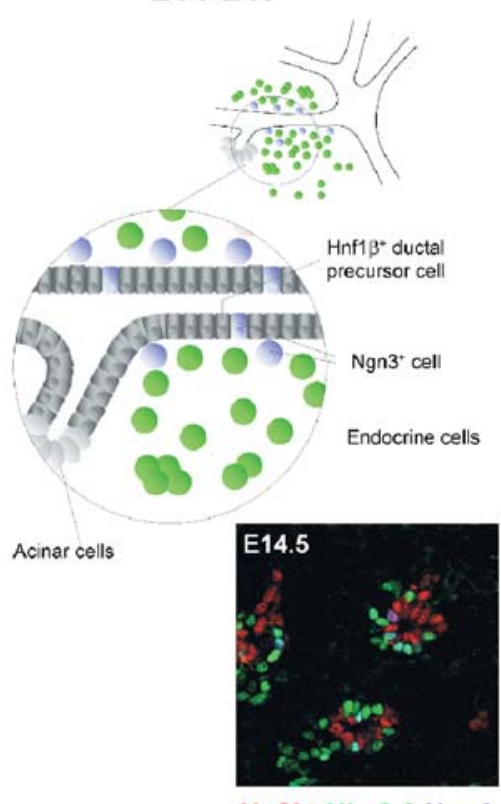

Adult pancreas

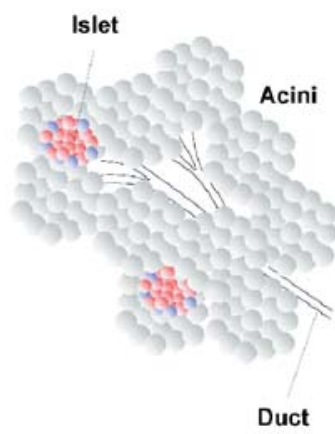

Fig. 2. Schematic representation of three stages of pancreatic development in the mouse embryo. At E9-E10 (left) dorsal and then ventral pancreatic buds arise from foregut endoderm. At this stage most epithelial cells are multipotent precursors expressing markers such as Pdx1 and Nkx2.2 (see also Fig. 3). The representative immunofluorescence image (E10.5) shows dorsal $(d p)$ and ventral $(v p)$ buds marked by anti-Nkx2.2 (green), while intense reactivity for anti-Hnfl $1 \alpha$ (red) identifies primitive liver (li). At E14-E17 (middle), the pre-differentiated epithelium has formed a well-defined ductal network distinguished from acinar and endocrine cells by the expression of Hnf1 $\beta$. Numerous $\mathrm{Ngn}^{+}$cells arise from the Hnf1 $\beta^{+}$ductal epithelium at this time, later giving rise to endocrine cells. The immunostaining image (E14.5) depicts ducts formed by Hnf $1 \beta^{+}$cells (red), $\mathrm{Ngn}^{+}$cells (blue) and endocrine cells expressing exclusively $\mathrm{Nkx} 2.2$ (green) (some cells co-express these markers, see main text). On the right is a schematic representation of the mature pancreas. Immunofluorescent stainings were provided by M. A. Maestro

transgenics using wild-type and mutated regulatory DNA segments linked to a reporter gene, or targeted mutations of cis elements to determine their role in the transcription of a gene at distinct developmental stages $[16,17,18]$.

A key issue in ChIP and expression profiling experiments is that relationships between transcription factors and target genes are highly cell-specific, and thus need to be demonstrated in specified cell types or developmental stages [19, 20,21]. Throughout this review, therefore, the emphasis is on direct regulatory interactions that have been shown to occur during defined cellular stages of the developing pancreas.
Hnf1 $\beta$ Nkx2.2 Ngn3

\section{Transcriptional networks in very early pancreatic bud multipotent cells}

In the mouse embryo, the first visible signs of pancreatic development appear at approximately embryonic day (E) 9 (Fig. 2) [3, 22]. Two pancreatic buds emerge independently from the ventral and dorsal regions of the foregut endoderm. The ventral bud is formed from cells that escape the inhibitory effect of fibroblast growth factor and bone morphogenetic protein signalling from the cardiac and septum transversum mesoderm [23, 24]. In contrast, signals from the notochord promote dorsal pancreas development through a process involving the repression of Sonic hedgehog expression in the dorsal endoderm [25, 26]. It is likely therefore that important aspects of the transcriptional programs orchestrating the specification and development of ventral and dorsal buds are distinct.

Fate-mapping and immunolocalisation studies have shown that most epithelial cells of the early buds are pre-differentiated precursors of exocrine and endocrine cells $[27,28,29]$. These cells express a combination of transcription factors, including Pdx1, Ptf1a (p48), Nkx6.1, Nkx2.2, Hb9, Hex, hepatocyte nuclear factor (Hnf) 6 and Foxa2 (Hnf3ß) [29, 30, 31, 32, 33, $34,35]$.

Knock-out studies show that many of these factors play essential roles in early buds (Fig. 3). Thus Pdx1 and Ptf1a are indispensable for the formation or progression of both buds $[29,36,37,38]$. On the other hand, $\mathrm{Hb} 9$ and Isl1 are only required for the specification or differentiation of the dorsal pancreatic bud, while Hex is selectively needed for specification of the ventral counterpart, which is consistent with the different mechanisms underlying the formation of the two buds $[33,35,39,40]$. Interestingly, at this stage 

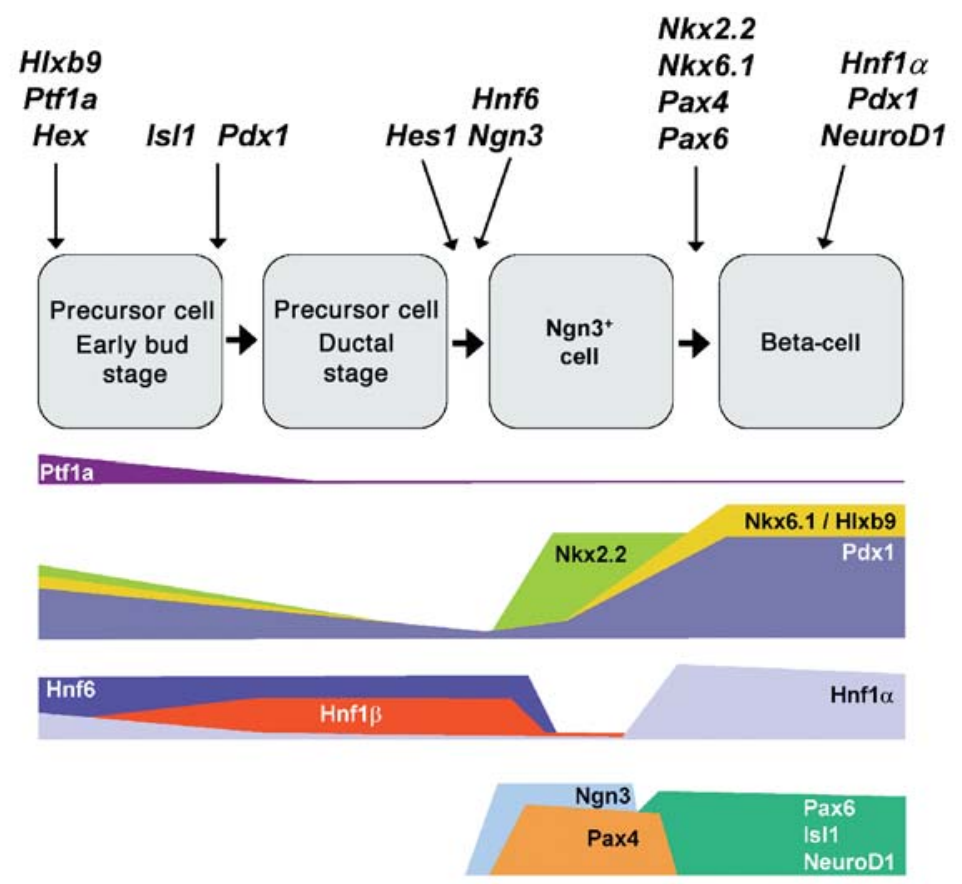

Fig. 3. Essential roles and expression patterns of transcription factors during different embryonic stages of the beta cell lineage. At the top, arrows point to the developmental steps at which the indicated transcription factors have been shown to be indispensable in genetic knock-out studies of mice, irrespective of when these genes are expressed. At the bottom the relative expression levels of different transcription factors throughout pancreatic development are indicated schematically

Isl1 is predominantly present in mesenchymal cells, and its mutant phenotype is due to lack of dorsal pancreas mesenchyme [39]. Hex contributes to the growth of ventral foregut endoderm so that part of it is at a site that is permissive for pancreatic organogenesis [35]. The findings for Isl1 and Hex show that the critical roles of transcription factors in pancreatic development can be mediated by completely indirect mechanisms that do not involve cell-autonomous activation of pro-differentiation genes in precursor epithelial cells.

There is thus considerable information on which transcription factors are expressed in pancreatic precursors and which ones are essential for early organogenesis. However, very little information is available at present on how transcriptional networks are organised within these cells. For example, nothing is known about the transcription factors that directly activate Ptfla, Nkx6.1, Nkx2.2 and Hlxb9 (Hb9) genes in the pancreatic primordium. There are also no data about their direct targets at this stage.

Information on the regulators and targets of Pdx 1 in early bud networks is at a more advanced stage. The importance of understanding the network linked to Pdx1 in pancreas organogenesis cannot be overstated. Pdx1 is not only essential for early pancreas for- mation [36], but can also activate pancreatic developmental programs if misexpressed in the right cellular context. Two laboratories have shown that $\mathrm{Pdx} 1$ can induce beta cell properties when expressed in adult or fetal liver cells [41, 42]. Another study demonstrated that a fusion protein containing the Xenopus orthologue of Pdx1 and the VP16 transcriptional activation domain can induce the formation of pancreatic tissue in the liver when misexpressed using the transthyretin promoter [43]. In this experiment VP16 provided a very strong activation domain, which probably acts as a surrogate for other activators that need to act in concert with Pdx 1 at common genomic targets.

So which transcription factors control the activation of $P d x l$ in early bud cells? It was recently shown that the activation of retinoic acid receptors during gastrulation specifies the location of Pdx 1 expression along the anterior-posterior boundary of the endoderm in zebrafish [44]. Moreover, Hb9 (in keeping with its role in the specification of dorsal pancreas) activates $P d x I$ in the dorsal region of the foregut by an unknown mechanism, while Hex 1 is indirectly required for $P d x 1$ expression in the ventral foregut [33, $35,40]$. Another recent study reported that the onecut homeodomain protein Hnf6 regulates $P d x l$ in the primordium [45]. Hnf6 is expressed in the foregut endoderm prior to $P d x 1$. Embryos lacking Hnf6 exhibit reduced expression of Pdx1 at E10 and delayed development of both ventral and dorsal pancreas, resulting in pancreatic hypoplasia (as well as other abnormalities discussed later) [45]. In vitro binding and cotransfection studies indicate that Hnf6 binds and transactivates mouse $P d x l 5^{\prime}$ flanking DNA [45], suggesting that Hnf6 is the first known direct regulator of Pdx 1 expression during early bud formation (Fig. 4). 

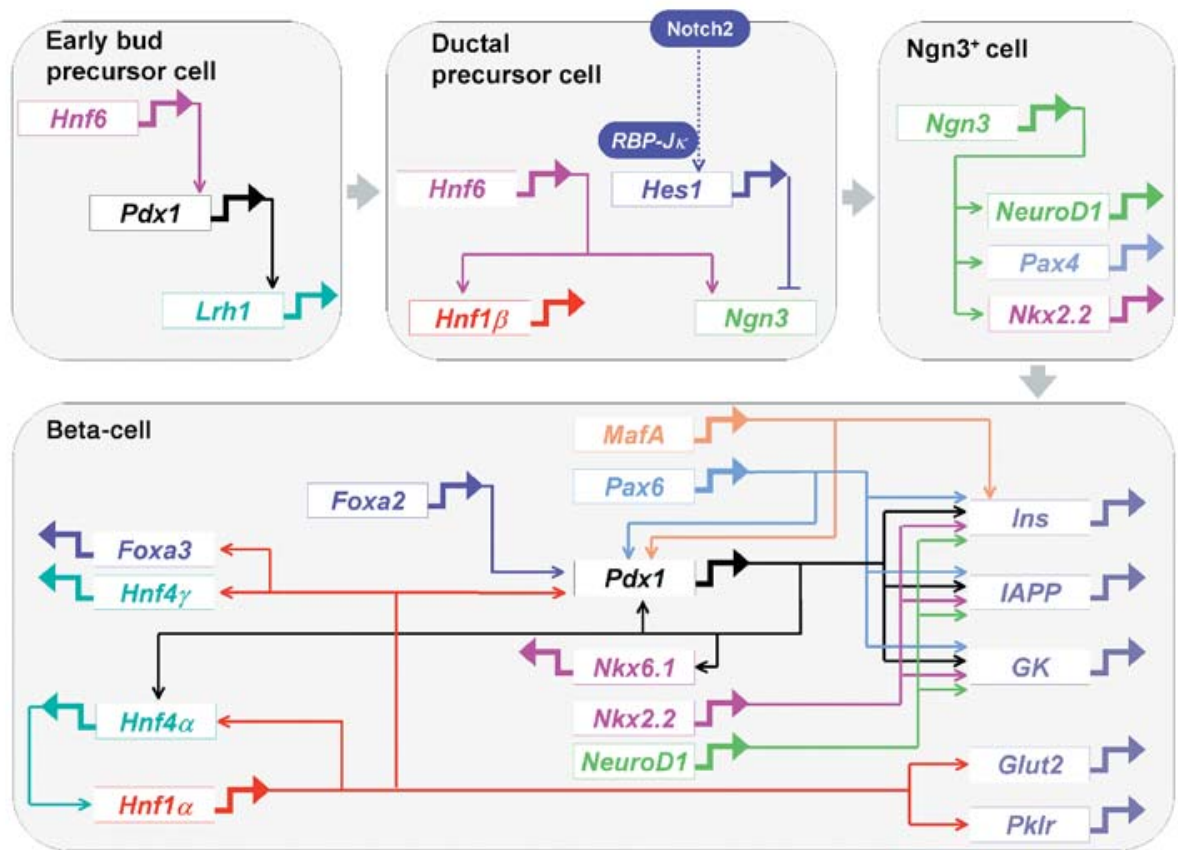

Fig. 4. Genetic networks during defined cellular stages of pancreatic development. The four compartments represent consecutive embryonic cellular stages analogous to those shown in Figure 3. Gene promoters are represented by a rectangle and a thick arrow. Binding of a transcription factor to a promoter is represented by a thin line. A perpendicular line replaces an arrow when an interaction is inhibitory. Only interactions shown to occur in vivo and for which there is biochemical evidence of a direct effect are depicted

The role of two other candidate regulators of $P d x l$ remains less well established. High-affinity binding of Pdx 1 to the $P d x l$ gene has been reported, consistent with an autoregulatory mechanism that operates once the gene is turned on $[46,47]$. However $P d x 1^{-/-}$mice exhibit apparently normal expression of a LacZ reporter knocked into the $P d x l$ locus in early bud cells [38]. Similarly, although Foxa2 (Hnf $3 \beta$ ) is expressed in the foregut and early pancreatic cells, and binds the $P d x l$ gene [47, 48], LacZ transgenics containing a mutation of a $P d x l$ gene-Foxa binding site affect expression in beta cells rather than in pancreatic rudimentary epithelial cells [49]. Cultured Foxa2 ${ }^{-1-}$ embryoid bodies exhibit reduced expression of $P d x I$ mRNA [50], but evidence of a similar role in the early embryonic pancreas is still lacking.

A different but equally crucial question is that of how Pdx 1 controls pancreas organogenesis. The identification of the genomic targets of Pdx 1 in early pancreatic buds should provide important clues in this regard. So far, the only direct target of Pdx1 reported at this stage is the nuclear receptor named liver receptor homologue 1 (Lrh1, NR5A2) [51]. This receptor is expressed in early bud epithelium, differentiated ducts and acinar cells [52]. Pdx1 was shown to bind to the Lrhl gene in vitro and in vivo in embryonic pancreas, and to transactivate episomal and endogenous Lrh1 in pancreatic carcinoma cells [51]. Furthermore, Lrhl mRNA is reduced in pancreatic buds of $P d x 1^{-1-}$ embryos at E9.5 (although, surprisingly, this study reported reduced expression in liver) [51]. Unfortunately Lrh $1^{-1-}$ embryos die before the pancreas is formed [51], so further experiments will be needed to define the possible role of $L r h 1$ as a downstream Pdx1 target. Other Pdx1-dependent genes are Hlxb9 (Hb9), which is induced by ectopic expression of Pdx 1 in chick embryo endoderm, and Sonic hedgehog, a negative regulator of pancreatic specification that is suppressed by Pdx1. However, it is not known if these effects are direct [53].

\section{The regulatory network controlling the formation of neurogenin $3^{+}$cells from embryonic duct precursor cells}

The embryonic mouse pancreas undergoes major changes by E13.5 to E17.5. The two buds fuse, and signs of acinar and endocrine differentiation become evident, while the remaining pre-differentiated cellular epithelium is organised into prominent branching ductal structures (Fig. 2) [3]. In addition to these morphological changes, the pre-differentiated duct epithelium differs from earlier $\mathrm{Pdx} 1^{+}$bud epithelial cells at the level of gene expression. Pdx1, Nkx2.2 and Nkx6.1 are visibly down-regulated (though still expressed), while Hnf6 and Hnf1 $\beta$ expression is maintained [34] (Fig. 2, Fig. 3, bottom panel). In fact, $\operatorname{Hnf} 1 \beta$ is slightly induced and serves as a specific marker for this ductal epithelial domain because it is not visibly expressed in differentiated acinar or endocrine cells [34].

The predominant wave of pancreatic endocrine cell generation takes place precisely at this embryon- 
ic stage $[54,55]$. Endocrine cells originate from lineage-committed progenitors that are marked by the helix-loop-helix transcription factor neurogenin 3 (Ngn3) [56]. Ngn $3^{+}$cells are present intercalated with Hnf $1 \beta^{+}$cells in the epithelium that lines the lumen of embryonic ducts, and in their immediate vicinity (Fig. 2) [34]. $\mathrm{Ngn}^{+}$progenitors are short-lived cells lacking a significant self-renewal capability [27]. This raises the question of which cells provide the precursor pool for $\mathrm{Ngn}^{+}$cells. Several observations, including the existence of frequent $\mathrm{Hnf} 1 \beta^{+} / \mathrm{Ngn}^{+}$ transition cells and the paucity of $\mathrm{Hnf} 1 \beta^{-} / \mathrm{Ngn}^{-}{ }^{-}$cells in embryonic duct epithelium, support the idea that $\mathrm{Hnf} 1 \beta^{+}$cells are the direct precursors of $\mathrm{Ngn}^{+}$cells [34]. The embryonic Hnf1 $\beta^{+}$duct cell domain probably also provides the precursors of differentiated pancreatic duct cells, as pancreatic ducts are essentially composed of Hnf $1 \beta^{+}$epithelial cells from E13.5 up to birth [34]. Thus, Hnf1 $\beta^{+}$ductal cells at E13.5 to E17.5 can be regarded as a distinct stage of embryonic precursors that immediately precedes the initiation of lineage-specific differentiation (Fig. 2, Fig. 3).

What are the transcriptional mechanisms controlling the generation of $\mathrm{Ngn}^{+}$cells within the $\mathrm{Hnf} 1 \beta^{+}$ epithelial domain? The current evidence points to the presence of positive and negative mechanisms regulating mutually exclusive pathways either to differentiation or to self-renewal of the $\mathrm{Hnfl}^{+}$epithelium. Hes1, a basic helix loop helix transcriptional repressor that is an effector of the Notch receptor signalling pathway, is a major negative regulator of endocrine cell commitment [57]. Thus, Hes1 homozygous null mutant embryos exhibit accelerated differentiation of $\mathrm{Ngn}^{+}$and endocrine cells, resulting in pancreatic hypoplasia due to early depletion of precursors [57]. This effect may be mediated through direct repression of the Ngn3 gene by Hes1 [58]. Hesl is activated by Notch receptor signalling, and accordingly the knockouts for the Notch pathway genes delta-like ligand 1 (dll1) or RBP-JK/CBF-1 exhibit phenotypes closely related to that of the Hes 1 knock-out [59]. In contrast, overexpression of activated Notch in embryonic precursors using $\mathrm{Pdx} 1$ promoter-driven transgenics suppresses both endocrine and exocrine differentiation $[60,61]$.

The inactivation of Notch/Hes1 in pancreatic duct precursors is therefore a decisive event for endocrine (and exocrine) differentiation. Accordingly, Hes 1 is absent in endocrine cells [62]. However, the mechanisms whereby Notch/Hes 1 is turned off in some precursor cells are unknown. One speculative scenario is that Ngn3 participates in this process, forming a negative cross-regulatory feedback loop. The activation of Ngn3 beyond a threshold in a given cell could thus result in the inhibition of its own repressor, hence consolidating commitment to the endocrine lineage. On the other hand, because Ngn3 turns on Notch ligand genes such as delta-like 1, activation of Ngn3 in a precursor cell is thought to suppress differentiation in the surrounding cells as a mechanism to modulate the number of endocrine cells being generated $[59,63,64]$.

The most prominent known positive regulator of $\mathrm{Ngn}^{+}$cell formation is Hnf6 [65]. Hnf6 is normally expressed in Hnf $1 \beta^{+}$duct epithelium and acinar cells, but not in endocrine cells $[30,34,65]$. The Hnf6 knock-out develops a pancreas but almost completely fails to generate $\mathrm{Ngn}^{+}$progenitors and endocrine cells during embryogenesis [65]. Moreover, Hnf6 interacts in vitro with a $5^{\prime}$ flanking cis element of the Ngn3 promoter and transactivates it in transient transfections [65]. It thus forms part of the program that induces the formation of $\mathrm{Ngn}^{+}$cells in concert with the inactivation of Notch signalling.

Another candidate key component of the Hnf $1 \beta^{+}$ precursor cell gene program is Hnf1 $\beta$. Embryos deficient in Hnf6 have markedly reduced Hnf $1 \beta$ in primitive pancreatic ducts, demonstrating that Hnf6 is an important regulator of Hnf $1 \beta$ in these cells [34]. Interestingly, Hnf6 also controls Hnf $1 \beta$ in the bile duct epithelium, and both Hnf6-deficient mice and liverspecific $\operatorname{Hnfl} \beta$ null mutants exhibit arrested bile duct differentiation, indicating that the Hnf6-Hnf1 $\beta$ hierarchy regulates bile duct differentiation [66, 67]. However, the exact role of $\operatorname{Hnf} 1 \beta$ in pancreatic ducts is still unclear. Whereas homozygous germ-line $\operatorname{Hnf} 1 \beta$ mutations cause embryonic death before the pancreas is formed [68, 69], heterozygous mice have not been reported to exhibit a phenotype. Yet humans with diabetes owing to heterozygous Hnfl $\beta$ mutations do exhibit pancreatic hypoplasia, which would be the expected phenotype, if $\operatorname{Hnf} 1 \beta$ acts as a regulator of pluripotent pancreatic precursor cells [70]. The Hnf6-Hnf1 $\beta$ hierarchy thus links two transcription factors with important pancreatic developmental phenotypes, suggesting that it is an integral component of an as yet incompletely understood genetic program that regulates the function of ductal precursor cells.

Intriguingly, the embryonic bile duct epithelium shares many of the transcriptional components with its pancreatic equivalent, including the Hnf6-Hnf1 $\beta$ hierarchy, expression of Hes1, and even Pdx1 [34, 38, 66, 71]. A striking recent report showed that Hesl-deficient embryos exhibit conversion of bile duct epithelium into a pancreas-like structure containing both acinar and islet endocrine cells, in a process that involves activation of Ngn3 [71]. Thus, embryonic pancreas and bile duct epithelium share a common intrinsic program capable of driving pancreatic differentiation. Unlike pancreatic duct cells, bile ductal cells normally suppress this program due to their inability to switch off Hes 1 expression. An understanding of the reasons for this difference could provide important clues on how to sort out the mechanisms underlying pancreatic differentiation. This finding also offers an extremely attractive potential route to induce the formation of beta cells in Type 1 diabetes. 


\section{Neurogenin 3 orchestrates a network that drives endocrine differentiation}

Mice lacking Ngn3 have no pancreatic endocrine cells [56], indicating that Ngn3 is not just a marker of progenitors, but also an essential effector. In fact, Ngn3 is sufficient to induce endocrine differentiation in appropriate cellular contexts $[53,59,63,72]$. Thus, transgenic overexpression of Ngn3 in early Pdx $1^{+}$cells results in massive endocrine differentiation, mostly glucagon cells [59, 72]. Similarly, electroporation of chick embryo endoderm with Ngn3 and Pdx1 gives rise to endocrine cells [53]. Again, glucagon but not insulin cells are generated, even if beta-cell-promoting factors such as Pax4 are added, indicating that the refinement of the endocrine subtype fate requires additional unidentified ingredients. In a different model, adenovirus was used to express Ngn3 in purified adult human ductal cells, resulting in expression of endocrine differentiation markers such as PC1, and even low levels of insulin [63].

The pro-endocrine role of Ngn3 results from the activation of several genes encoding endocrine differentiation regulators. Thus, in the human duct study described above, forced expression of Ngn3 induced expression of endocrine transcription factors NeuroD1, Pax4, Nkx2.2 and Pax6 [63], while in the Ngn3 knock-out [56] a similar set of genes became inactive.

Many of the Ngn3-dependent, pro-endocrine regulators are direct genomic targets. In vitro Ngn3 binds and transactivates the $5^{\prime}$ flanking region of NeuroDl (Beta2), another cell-restricted basic helix-loop-helix transcription factor gene that regulates the survival and terminal differentiation of beta cells [73]. NeuroD1 is likely to be directly responsible for part of the pro-endocrine effects of Ngn3, given that its misexpression in precursor cells of transgenic embryos or in human ducts partially mimics the effects of Ngn3 $[63,72]$.

Neurogenin 3 also binds and transactivates a cis element in the Pax4 promoter [74], while $\mathrm{Ngn3}^{-1-}$ mice fail to express Pax4 mRNA [56], suggesting that Pax4 is also a direct target of Ngn3. During embryogenesis, Pax4 is only transiently expressed in progenitors (Fig. 3). Its function is to sub-specify the beta cell type within the endocrine progenitor pool [75]. Interestingly, one role of Pax4 is to directly or indirectly suppress the expression of another transcription factor, Arx, whose function is to promote the alpha rather than beta cell fate of $\mathrm{Ngn}^{+}$progenitors [76].

Another Ngn3 target, $N k x 2.2$, also drives endocrine differentiation. The regulation of $N k x 2.2$ is somewhat complex. Nkx2.2 is expressed at low levels in predifferentiated epithelial cells, then exhibits a sharp induction in $\mathrm{Ngn}^{+}$cells and remains highly expressed in endocrine cells [32, 34, 64, 77] (Fig. 3). $N k x 2.2$ is controlled by alternative promoters at different cellular stages [78]. Immediately after the $\mathrm{Ngn}^{+}$stage, promoter 1a drives $\mathrm{Nkx} 2.2$ expression in endocrine cells [78]. It has been suggested that Ngn3 and NeuroD 1 consecutively activate Nkx 2.2 through this promoter in progenitor and endocrine cell stages, a suggestion based on the presence of $\mathrm{E}$ boxes that are bound and transactivated by these factors [78]. In contrast, promoter $1 \mathrm{~b}$ is activated in $\mathrm{Ngn}^{+}$progenitor cells and probably requires a separate activation mechanism parallel to the induction of Ngn3, while the cis regulatory elements involved in the earlier bud cells are less well characterised [78].

Even though Nkx2.2 is present in pancreatic epithelium prior to the activation of Ngn3, its first essential role is not until the immediate post-Ngn3 stage (Fig. 3). The inactivation of $N k x 2.2$ gives rise to endocrine-like cells lacking insulin or Glut2 but expressing other endocrine markers such as amylin and Isl1, which suggests that the endocrine differentiation process is blocked or diverted [32]. In contrast, inactivation of another homeodomain transcription factor, $N k x 6.1$, results in a severe reduction of insulin-producing cells [31]. Remarkably, $N k x 2.2 / N k x 6.1$ double knock-outs entirely mimic the $N k x 2.2$ mutant pancreatic phenotype [31], suggesting that the essential role of Nkx6.1 takes place after the step controlled by Nkx2.2.

Interestingly, Ngn3 has also been shown to negatively regulate its own promoter in transient transfection studies, providing a potential mechanism for selfinactivation that is consistent with its transient expression during pancreatic development [79].

\section{Pdx1, a critical regulator of the differentiated beta cell phenotype}

Once beta cells are formed during pancreatic development, genetic programs are needed to carry out their specialised functions. One obvious function of such programs is to support high levels of insulin gene transcription. Another equally important task is to activate a vast number of genes involved in (i) the sensing of extracellular signals such as nutrients, hormones and neurotransmitters; (ii) the coupling of these signals to the process of secretion; and (iii) the regulation of beta cell mass or the ability to respond to immune-mediated damage [80, 81, 82].

In addition to its role in early organogenesis, $\mathrm{Pdx} 1$ is also a key regulator of differentiated beta cells. Shortly after the Ngn $3^{+}$cell stage, Pdx1 is sharply induced in insulin-producing cells and remains highly expressed throughout adult life (Fig. 3). Targeted disruption of the $P d x l$ gene in mature beta cells leads to a diabetic phenotype due to impaired beta cell function $[6,83,84]$. This is associated with reduced activity of islet-specific genes regulated by $\mathrm{Pdx} 1$ such as insulin, IAPP, Nkx6.1 and Glut2 [6, 84]. A similar expression profile results from dominant negative 
suppression of Pdx1 in INS1 beta cells [85]. In vitro binding and transient transfection studies suggest that $\mathrm{Pdx} 1$ interacts directly with the $5^{\prime}$ flanking regions of these four genes [86, 87, 88, 89], while ChIP experiments have confirmed that Pdx1 binds in vivo to the insulin and IAPP genes in cultured beta cell lines [90, 91].

The key role of Pdx 1 in beta cells is further emphasised by mouse and human genetic studies showing that beta cells are sensitive to $P d x l$ gene dosage. Thus heterozygous mutant mice exhibit beta cell dysfunction and diabetes associated with defective expression of Glut2, IAPP and Nkx6.1 [92, 93], as well as increased apoptosis [94], whereas in humans heterozygous IPF1 (Pdx1) mutations lead to Maturity onset diabetes of the young (MODY) 4 [95].

\section{How is cell-specific, high-level Pdx1 expression achieved in beta cells?}

Given the pre-eminent role of Pdx1 in differentiated beta cell function, it is not surprising that the regulation of the $P d x 1$ gene in these cells has attracted considerable interest. Numerous transgenic and cell culture studies have by now established that the cell-specific transcription of the $P d x l$ gene is mediated by several cis regulatory areas located at more than $1.6 \mathrm{~kb}$ from the transcription site, most of which are evolutionarily conserved [48, 96, 97].

Several regulators of $P d x I$ in beta cells have been identified, one of which is Foxa2. As mentioned earlier, in vitro binding studies and transient transfection studies have identified multiple Foxa2-binding sites in the distant $5^{\prime}$ flanking regions of human, mouse and rat Pdx1 genes [47, 48, 50, 97, 98], while ChIP analysis has shown that Foxa2 binds to the mouse Pdx1 distant enhancer region in beta cell lines [49]. Transgenic experiments have shown that the so-called Area II of the $P d x 1$ distant $5^{\prime}$ flanking region, which contains one of the high-affinity Foxa2-binding sites, can drive beta-cell-specific expression, whereas mutation of the Foxa2-binding site reduced beta cell expression penetrance of another transgene [49]. Furthermore, betacell-specific ablation of Foxa2 with the Cre/loxP system results in down-regulation of islet $P d x 1 \mathrm{mRNA}$ and protein levels [99].

Recently, the beta-cell-enriched MafA basic-leucine zipper protein was found to bind to a conserved $P d x l$ Area II sequence in vitro and in vivo in a beta cell line [100]. Transient transfection studies with substitution mutants of the $P d x l$ gene Maf-binding site suggest that MafA exerts positive regulation of this gene in cultured beta cell lines [100]. The same region is bound by Pax6 in beta cell lines, both in vitro and in vivo, and mutational analysis of the Pax6-binding site suggests that it too is a positive regulator of the $P d x I$ gene [49].
As mentioned earlier, some data point to autoregulation of Pdx1, a finding based on the in vitro [47] and in vivo binding of Pdx1 to a conserved distant enhancer region of $P d x l$ in cultured beta cells [46, 90]. The physiological consequences of this loop in beta cells are still unclear, as $\mathrm{Pdx} 1^{+/-}$islets exhibit, as expected, roughly 50\% expression of Pdx 1 mRNA, whereas some existing studies have proposed either positive or negative regulatory effects $[46,47,83$, 93].

Hnf1 $\alpha$, a POU-homeodomain protein involved in MODY3, binds in vitro to the mouse and human $P d x 1$ genes $[46,98]$. The genetic data on the functional consequences of this interaction are somewhat controversial. Whereas one study showed a 2.9-fold reduction of Pdx1 mRNA in islets of $H n f l \alpha^{-1}$ mice [21], two others failed to show this in young Hnfl $\alpha^{-/-}$mice [19, 101] (the latter [101] did find a reduction after 6 weeks of age). Moreover, dominant negative suppression of Hnf1 $\alpha$ in INS1 cells fails to inhibit Pdx1 mRNA [102]. Potential explanations of these discrepancies include (i) the effects of diverse genetic backgrounds, and (ii) the suggestion that $\operatorname{Hnf} 1 \alpha$ is required after a certain postnatal stage and/or that the observed effects are secondary to hyperglycaemia.

So far, in short, no single factor has been found to be absolutely indispensable for Pdx 1 expression in beta cells. On the other hand, recent studies have revealed a combination of cell-specific transcriptional activators that bind to the Pdx1 gene, many of which are involved in ensuring high levels of expression in beta cells.

\section{A signalling cascade acting through $P d x 1$}

Recent studies have provided interesting insights into how signalling cascades can mediate their effects through the modulation of beta cell transcription networks. A revealing example is the regulation of $P d x 1$ by Irs2 and Foxo1, two transducers of key extracellular signals such as insulin and IGF1 [103].

Several genetic experiments support the proposal that Irs2 is required for Akt to phosphorylate the forkhead transcription factor Foxo1, which is then excluded from the nucleus and prevented from inhibiting the $P d x l$ gene. Irs $2^{-l-}$ mice thus exhibit reduced phosphorylation of Foxo1 and diminished expression of Pdx1 [104, 105]. Haplo-insufficiency for Foxo1 partially restores the expression of $\mathrm{Pdx} 1$ and reverses beta cell failure caused by Irs2 deficiency. Moreover, a constitutively active Foxo 1 mutant inhibits Pdx1 expression in beta cells [106].

The mechanism whereby Foxo1 exerts this negative effect on the $P d x l$ gene is not known, although one suggestion is that it inhibits Foxa2-dependent regulation of $P d x l$ [104]. On the other hand, the extent to which the IRS2 and Foxo1 findings relate to 


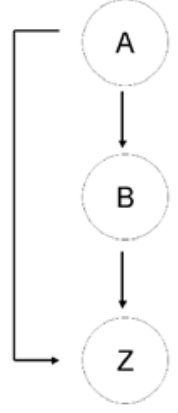

Feedforward motif

Fig. 5. Basic regulatory motifs in genetic networks. Certain patterns of regulation between transcription factor genes are over-represented in gene networks. Circles represent transcription factor genes, arrows show that a gene product exerts direct control of another gene or its own gene. This figure is largely based on data presented in references [128, 129]

insulin and IGF1-dependent signalling has yet to be established. Beta-cell-specific knock-outs for insulinand IGF1-receptor genes have reduced beta cell function, but this has not been reported to result in reduced $P d x 1$ expression [107, 108, 109, 110]. Future studies will thus need to further define the precise signals and regulatory contexts that drive Irs2/Foxo1 regulation of the $P d x l$ gene.

\section{Multi-input motifs control the transcription of beta-cell-specific genes}

Much of what we know about the transcriptional control of beta cells stems from a wealth of studies that analysed the cis and trans elements involved in insulin gene transcription $[111,112]$. Three major pancreatic transcription factors were discovered precisely because of their ability to bind to several evolutionarily conserved sites in the insulin gene promoter, namely Pdx1 [113], MafA [114, 115] and NeuroD1/ Beta2 [116], although these same factors were also independently cloned through other routes $[117,118$, $119,120,121]$. Subsequent in vivo studies have verified that all three factors occupy insulin gene chromatin in cultured beta cell lines [90, 91, 115]. As discussed earlier, $\mathrm{Pdx} 1$ is essential for normal insulin gene expression in mouse beta cells [6, 83, 84]. The MafA knock-out has not been reported on, although cell culture studies indicate that one major role may be related to glucose induction of insulin gene transcription [120], while transgenic studies analysing a DNA rat insulin promoter 3 element, to which MafA binds, suggest that it contributes to cell-specific expression [122]. Surprisingly, homozygous NeuroDl mutant mice showed that this gene is not indispensable for insulin gene expression, despite numerous functional studies in cultured cell lines indicating that it plays a regulatory role in rodent and human insulin genes $[116,123,124,125]$. To date, no detailed analysis of these mice has determined whether insulin mRNA content is partially reduced or whether the physiological regulation of insulin gene expression is impaired.

Two other factors that bind the insulin gene in vitro and in vivo in cultured beta cell lines are $\mathrm{Nkx} 2.2$ and Pax6 [91]. As discussed earlier, Nkx2.2 is essential for insulin gene activity in mice [32], and in one of the two Pax6 mutants marked reductions of insulin gene expression were observed [126]. Thus, analogously to the situation described for the $P d x l$ gene, beta-cellspecific activation of the insulin gene is dependent on a unique combination of nuclear factors occupying its $5^{\prime}$ flanking region in beta cells.

Remarkably, a nearly identical collection of transcription factors (i.e. Pdx1, Pax6, NeuroD1, Nkx2.2) has been reported to occupy a set of beta cell promoters that includes glucokinase, IAPP and Pax4 [91, 127] (Fig. 4). This pattern, whereby multiple factors control a common set of genes, is a characteristic motif encountered in transcription networks and referred to as a multi-input motif [128, 129] (Fig. 5). It has been suggested that such multi-input motifs confer the ability to provide coordinated gene responses to diverse regulatory signals [128], but they can also more simply underlie the combinatorial code required to activate a particular set of cell-specific genes. On the other hand, MafA and Pax6 both regulate the insulin gene as well as Pdx1 [49, 91, 100, 115], which itself is a regulator of the insulin gene. Feed-forward motifs of this sort are thought to serve as a switch, capable of responding to sustained rather than transient inputs (the distal target gene is activated only if a previous input has enabled expression of the intermediate gene) $[128,129,130,131]$. It could therefore be speculated that such motifs modulate insulin transcription as a function of long-term metabolic demands.

Collectively these results show that the transcription of the insulin gene results from the concerted action of a complex non-lineal beta-cell-specific network. While several major components of this network have been identified, the regulatory logic of its structure is not yet understood. 


\section{Several MODY genes play key roles in a common differentiated beta cell network}

The genetic analysis of MODY has provided a mine of previously unsuspected information on beta cell transcription networks. We now know that MODY is caused by heterozygous mutations in at least five genes encoding transcription factors: $H N F 4 \alpha / H N F 4 A$ (MODY1), HNF1 $/ T C F 1$ (MODY3), PDX1/IPF1 (MODY4), HNf1 $\beta / T C F 2$ (MODY5) and NEUROD1/ BETA2 (MODY6) [95, 124, 132, 133, 134] (reviewed in references [14] and [13]). MODY2, which is so far the only subtype not related to a transcription factor [135], is caused by mutations in the glucokinase gene.

MODY is essentially a haplo-insufficient phenotype, based on functional studies showing that most mutations are loss-of-function defects and that disease-causing mutations exist in promoter regions [7, 136, 137, 138, 139, 140]. Mutation carriers develop a severe impairment of insulin secretion and diabetes after at least 10 years of age [141, 142, 143]. Interestingly, beta cell dysfunction does not result from the sheer lack of insulin, as elegantly shown in a recent human therapeutic trial. This trial [144] revealed that MODY3 patients retain a considerable ability to secrete insulin in response to sulphonylureas. This suggests that $\mathrm{Hnf} 1 \alpha$ controls specific differentiated functions of beta cells, rather than solely the beta cell mass or insulin gene transcription.

Hnfl $\alpha^{-1-}$ mice are viable, and have thus turned out to be a very fruitful model to understand the function of MODY transcription factors in beta cells [19, 20, $21,145,146,147]$. These mice have abnormal glucose-induced insulin release and develop diabetes shortly after birth, in addition to other metabolic abnormalities in the liver and kidney $[145,146]$. Reduced nutrient-induced insulin release in Hnf1 $\alpha$-deficiency has been linked to impaired islet glucose metabolism [102, 147, 148]. A number of beta cell targets of Hnf $1 \alpha$ have been identified, e.g. Glut 2 and L-pyruvate kinase $(P k l r)$, but the role of specific gene defects in the stimulus-secretion coupling phenotype of Hnf1 $\alpha$-deficient islets is unclear $[19,20,102,147$, 148]. Interestingly, mRNA levels of several beta cell targets such as Glut2 and Pklr are not reduced in hepatocytes or pre-differentiated pancreatic cells from $H n f l \alpha^{-/}$mice, suggesting that the role of Hnfl $\alpha$ is highly dependent on the developmental and cell-typespecific context [19].

Islets from Hnfl $\alpha^{-1-}$ mice exhibit decreased expression of several transcription factor mRNAs, including $H n f 4 \alpha, H n f 4 \gamma, S h p$ and Foxa3, pointing to the existence of a broad Hnfl $\alpha$-dependent transcriptional network [20, 21]. Being also a MODY gene, $H n f 4 \alpha$ is a particularly interesting transcription factor target. Importantly, $H n f 4 \alpha$ mRNA is dependent on Hnfl $\alpha$ specifically in differentiated pancreatic cells, but not in the liver [20]. This is because in the pancreas the
$H n f 4 \alpha$ gene is almost exclusively driven by the P2 promoter, which is bound and controlled by $\operatorname{Hnf} 1 \alpha$, whereas in the liver and most other tissues $H n f 4 \alpha$ is predominantly driven by the $\mathrm{P} 1$ promoter, which does not require $\operatorname{Hnf} 1 \alpha[20,149,150]$.

The tissue specificity of Hnfl $\alpha$-dependent expression of $H n f 4 \alpha$ is concordant with the common beta cell phenotype in MODY due to mutations in these two genes. This suggests that Hnf $1 \alpha$ control of $H n f 4 \alpha$ P2 promoter could be a critical regulatory link in beta cells. This is strongly reinforced by the identification of a natural human mutation in the $H N F 4 \alpha \mathrm{P} 2$ promoter that selectively impairs binding by $\operatorname{Hnf} 1 \alpha$ and causes diabetes [138]. What is remarkable about this mutation is that although $\operatorname{Hnf} 1 \alpha$ regulates multiple genes in beta cells, the selective disruption of its regulation of $H n f 4 \alpha$ has similar consequences to mutations that completely disrupt $\operatorname{Hnf} 1 \alpha$ function [138]. On the other hand, this Hnfl site mutation is one of three reported genetic defects that disrupt P2 promoter function and cause MODY [149, 151], and together they provide compelling confirmation that this is the biologically significant $H n f 4 \alpha$ promoter in the pancreas, despite the fact that P1-driven transcripts can be detected by PCR in human islet RNA [152] (S.F. Boj and J. Ferrer, unpublished).

Regulation in the opposite direction, i.e. the regulation of $H n f l \alpha$ by Hnf $4 \alpha$, also occurs. However, in this case there is no beta cell selectivity. The germ-line $H n f 4 \alpha$ knock-out is lethal at a very early embryonic stage [153], but Hnf $1 \alpha$ expression is reduced in $H n f 4 \alpha^{-1-}$ embryoid bodies [136], in $H n f 4 \alpha$-deficient hepatocytes from chimeric mutant embryos [154], and in a Cre/loxP-based $H n f 4 \alpha$ liver-specific knock-out (Iannis Taliandidis, unpublished observations). In vitro and in vivo transgenic studies have shown that regulation of the Hnfl $\alpha$ gene by $\mathrm{Hnf} 4 \alpha$ is dependent on an evolutionarily conserved cis sequence element in the Hnfl $\alpha$ promoter $[17,155,156]$. Support for the notion that $\mathrm{Hnf} 4 \alpha$ controls Hnfl $\alpha$ expression both in liver and in pancreatic cells comes from a human mutation in this same conserved cis element that co-segregates with MODY in a large pedigree [140]. Furthermore, dominant negative suppression of $\mathrm{Hnf} 4 \alpha$ in INS1 cells decreases expression of $\mathrm{Hnf} 1 \alpha$, resulting in inhibition of the same mRNAs as dominant negative suppression of Hnf1 [4]. Thus, Hnfl $\alpha$ is dependent on $\mathrm{Hnf} 4 \alpha$ in numerous cell types, but specifically in pancreatic cells the two genes are interdependent.

The Hnf $1 \alpha-H n f 4 \alpha$ positive cross-regulatory loop could act as a cellular memory mechanism that maintains the expression of the two genes and their targets in differentiated pancreatic cells. Other self-sustaining cross-regulatory circuits connecting MODY genes are also likely to operate in beta cells. For example, Hnfl $\alpha$ mRNA is reduced in $P d x 1^{+/-}$mice [93], while in some studies discussed earlier Pdxl and NeuroDl mRNA was reduced in Hnfl $\alpha^{-1-}$ mice [21]. A regula- 
tory interaction of some sort between $P d x I$ and $H n f l \alpha$ is further supported by the finding that $P d x I^{+/-}$ $H n f l \alpha^{+-}$double heterozygous mice exhibit a more severe beta cell defect than expected from the sum of the single heterozygous defects [93]. The regulation of $\operatorname{Pdx} 1$ by $\operatorname{Hnf} 4 \alpha$ has not yet been analysed, but Pdx 1 interacts in vitro with a TAAT element in the $H n f 4 \alpha$ P2 promoter and transactivates it in transient transfections [149]. A mutation in this cis element causes MODY in a large pedigree, indicating that the sequence is essential for $H n f 4 \alpha$ promoter activity [149].

\section{MODY as a paradigm of a haplo-insufficient defect resulting from the breakdown of cell-specific networks}

One of the outstanding questions in the genetics of MODY is why heterozygous mutations in genes like $H N F 1 \alpha$ or $H N F 4 \alpha$ cause a phenotype essentially restricted to beta cells, whereas homozygous mutations give rise to phenotypes affecting numerous other cell types $[7,153,157,158]$. The resolution of this paradox may reside in the fact that these transcription factors form part of different networks in distinct cell types. The network operating in beta cells may be sensitive to haplo-insufficiency, whereas other networks need not be affected.

It is thus worth reflecting on the consequences of reduced gene dosage in the context of the pancreasselective Hnf $1 \alpha-\mathrm{Hnf} 4 \alpha$ circuit configuration [7]. Positive cross-regulatory loops like this one (gene A is dependent on B, gene B is dependent on A) typically exhibit bistable behaviour $[9,159,160]$. By this we mean that reciprocal activation between two genes (such as $\operatorname{Hnf} 1 \alpha$ and $\mathrm{Hnf} 4 \alpha$ ) can serve to maintain the activity of both genes in a very stable state. However, because they are interdependent, a transient reduction of either gene that is severe enough to fall below a certain threshold can lead to a severe inhibition of the other gene. This results in an alternate stable state, in which the two genes are expressed at a level below that required to activate each other [160]. Reduced gene dosage of Hnfl $\alpha$ or $H n f 4 \alpha$ could therefore increase the probability that the transition from the active to the inactive stable state occurs due to the diminished ability of a one-allele system to prevent severe transient reductions of a gene product $[7,161$, 162]. In such a scenario, a germ-line mutation that disrupts a single $H n f l \alpha$ or $H n f 4 \alpha$ allele can lead to the stable functional knockdown of all four alleles that compose the circuit. This is expected to occur selectively in cells where the two genes are interdependent, in keeping with the cellular-specificity of MODY.

MODY thus apparently results from the collapse of cell-specific transcriptional networks due to the haploinsufficiency of key network genes. In fact, the genet- ic analysis of MODY may have helped to reveal not only unsuspected beta cell transcription factors, but also the keys to understand the functional logic of underlying regulatory networks.

\section{Pancreatic transcription networks as complex systems}

As more knowledge is gained about pancreatic transcription networks, it will become theoretically possible to interpret general aspects of their behaviour, and not solely their individual components. Studies in much more manageable models than the mammalian pancreas, such as Escherichia coli and Saccharomyces cerevisiae, have provided enough data to indicate that transcription factors that control most cellular functions form complex networks [128, 129, 130, 163]. It is thus worth considering some overarching principles governing the behaviour of complex networks.

One interesting notion is that networks as diverse as the Internet, ecological webs or transcription and metabolic networks are generally arranged in a highly non-random manner [130, 164, 165]. A very common non-random configuration is known as the scale-free network. In such a network a few nodes are disproportionately highly connected to other nodes, whereas most nodes have very few links [164]. Such networks are extremely robust inasfar as the individual loss or change in behaviour of most nodes have few consequences. However, selective inactivation of the few highly interconnected nodes can be catastrophic [164]. It will be interesting to see to what extent this concept applies to pancreatic networks as well as potentially to the fact that some transcription factor mutations in mice and humans with pancreatic transcription factor loss of function lead to particularly severe pancreatic phenotypes, whereas others appear to be inconsequential.

Another interesting non-random feature of most complex networks is the over-representation of connectivity patterns or "motifs" [128, 129, 130]. Experimental studies have shown that transcription factor networks in particular possess a disproportionately high representation of certain motifs such as feedforward loops, autoregulation, multi-component feedback loops or multi-input motifs [128, 129, 130] (Fig. 5). Of particular interest is a landmark study that used ChIP-on-chip to identify the in vivo binding sites in the $S$. cerevisiae genome for 106 of the 141 known $S$. cerevisiae transcription factors [128] (schematic description of ChIP-on-chip, see Fig. 1). This study provided a bird's eye view of the topology of a transcription network in a eukaryotic cell and showed that transcription factor genes are highly interconnected, with frequent well-defined regulatory motifs such as those shown in Fig. 5, as well as highly connected hub-like nodes [128]. 
Interestingly, similar motifs have also been encountered in pancreatic networks, as discussed in this review. Experimental and mathematical modelling data suggest that such over-represented motifs fulfil specific regulatory strategies, some of which have been discussed earlier in this review [9, 129, 130, $131,159]$. In some cases, motifs or combinations of motifs form modules whose function can be analysed independently of the remaining network [166]. In fact, it is possible that an understanding of the function of large networks can, to a large extent, be achieved through careful hypothesis-driven analysis of key modules. Resources such as ChIP-on-chip screens could thus provide the "road maps" that describe the global network topology and help identify unsuspected subnetworks.

\section{Concluding remarks}

The development of the pancreas is controlled by transient networks that operate during consecutive precursor cell stages. Specific gene networks are also in place to provide long-term maintenance of the differentiated beta cell phenotype. The past few years have seen unprecedented progress in our understanding of pancreatic networks, largely through the testing of focused hypotheses. Further advances are expected in the field as a consequence of large-scale gene expression, ChIP, proteomics and mutation screens. The significance of these studies will be determined by whether they can be applied to the major developing and adult pancreatic cell types, as opposed to transformed cell lines or heterogeneous cellular populations.

From what is already known, it is apparent that most pancreatic transcription networks are not simple lineal hierarchies, but complex networks analogous to those recently described in more simple cellular models. Further complexity is to be expected from the integration of gene networks with other regulatory networks, including those formed by signal transduction pathways and protein-protein interaction webs. We believe that an approach combining the availability of large-scale network maps with more focused hypothesis-driven experimentation will eventually provide an in-depth understanding of the behaviour of pancreatic networks that is concordant with the complex biological reality. This in turn should provide foundations for the development of new therapies for beta cell loss and dysfunction in human diabetes.

Note added in proof. While the manuscript was in press, Odom et al. (Science 303:1378-1381, 2004) have reported a study which analyses the in vivo binding sites of Hnfl $\alpha, H n f 4 \alpha$ and Hnf6 in hepatocytes and islet-enriched pancreatic tissue using chromatin immunoprecipitations and a microarray containing the upstream regions of 13000 human genes.
Acknowledgements. Work in the authors' laboratory was funded by the Juvenile Diabetes Research Foundation, the European Commission, the Spanish "Ministerio de Ciencia y Tecnología" and the "Instituto de Salud Carlos III" (also Spain). We thank S. Boj, M. A. Maestro, J. Cabedo, R. Luco and C. Cardalda for encouraging discussions and M. German and I. Talianidis for sharing unpublished data.

\section{References}

1. Cavaleri F, Scholer HR (2003) Nanog: a new recruit to the embryonic stem cell orchestra. Cell 113:551-552

2. Pesce M, Scholer HR (2001) Oct-4: gatekeeper in the beginnings of mammalian development. Stem Cells 19:271278

3. Edlund H (2002) Pancreatic organogenesis-developmental mechanisms and implications for therapy. Nat Rev Genet 3:524-532

4. Wang H, Maechler P, Antinozzi PA, Hagenfeldt KA, Wollheim CB (2000) Hepatocyte nuclear factor 4alpha regulates the expression of pancreatic beta -cell genes implicated in glucose metabolism and nutrient-induced insulin secretion. J Biol Chem 275:35953-35959

5. Shih DQ, Stoffel M (2001) Dissecting the transcriptional network of pancreatic islets during development and differentiation. Proc Natl Acad Sci USA 98:14189-14191

6. Ahlgren U, Jonsson J, Jonsson L, Simu K, Edlund H (1998) Beta-cell-specific inactivation of the mouse Ipf1/ Pdx1 gene results in loss of the beta-cell phenotype and maturity onset diabetes. Genes Dev 12:1763-1768

7. Ferrer J (2002) A genetic switch in pancreatic beta-cells: implications for differentiation and haploinsufficiency. Diabetes 51:2355-2362

8. Edlund T, Jessell TM (1999) Progression from extrinsic to intrinsic signaling in cell fate specification: a view from the nervous system. Cell 96:211-224

9. Smolen P, Baxter DA, Byrne JH (2000) Mathematical modeling of gene networks. Neuron 26:567-580

10. Lechner A, Habener JF (2003) Stem/progenitor cells derived from adult tissues: potential for the treatment of diabetes mellitus. Am J Physiol Endocrinol Metab 284:E259-E266

11. Efrat S (2002) Cell replacement therapy for type 1 diabetes. Trends Mol Med 8:334-339

12. Soria B, Skoudy A, Martin F (2001) From stem cells to beta cells: new strategies in cell therapy of diabetes mellitus. Diabetologia 44:407-415

13. Fajans SS, Bell GI, Polonsky KS (2001) Molecular mechanisms and clinical pathophysiology of maturity-onset diabetes of the young. N Engl J Med 345:971-980

14. Owen K, Hattersley AT (2001) Maturity-onset diabetes of the young: from clinical description to molecular genetic characterization. Best Pract Res Clin Endocrinol Metab 15:309-323

15. Orlando V, Paro R (1993) Mapping Polycomb-repressed domains in the bithorax complex using in vivo formaldehyde cross-linked chromatin. Cell 75:1187-1198

16. Gannon M, Gamer LW, Wright CV (2001) Regulatory regions driving developmental and tissue-specific expression of the essential pancreatic gene pdx1. Dev Biol 238:185-201

17. Ryffel GU, Lingott A (2000) Distinct promoter elements mediate endodermal and mesodermal expression of the HNF1alpha promoter in transgenic Xenopus. Mech Dev 90:65-75 
18. Li Song D, Joyner AL (2000) Two Pax2/5/8-binding sites in Engrailed2 are required for proper initiation of endogenous mid-hindbrain expression. Mech Dev 90:155-165

19. Parrizas M, Maestro MA, Boj SF et al. (2001) Hepatic nuclear factor 1-alpha directs nucleosomal hyperacetylation of its tissue-specific transcriptional targets. Mol Cell Biol 21:3234-3243

20. Boj SF, Parrizas M, Maestro MA, Ferrer J (2001) A transcription factor regulatory circuit in differentiated pancreatic cells. Proc Natl Acad Sci USA 98:14481-14486

21. Shih DQ, Screenan S, Munoz KN et al. (2001) Loss of HNF-1alpha function in mice leads to abnormal expression of genes involved in pancreatic islet development and metabolism. Diabetes 50:2472-2480

22. Wells JM, Melton DA (1999) Vertebrate endoderm development. Annu Rev Cell Dev Biol 15:393-410

23. Deutsch G, Jung J, Zheng M, Lora J, Zaret KS (2001) A bipotential precursor population for pancreas and liver within the embryonic endoderm. Development 128:871-881

24. Rossi JM, Dunn NR, Hogan BL, Zaret KS (2001) Distinct mesodermal signals, including BMPs from the septum transversum mesenchyme, are required in combination for hepatogenesis from the endoderm. Genes Dev 15:19982009

25. Apelqvist A, Ahlgren U, Edlund H (1997) Sonic hedgehog directs specialised mesoderm differentiation in the intestine and pancreas. Curr Biol 7:801-804

26. Hebrok M, Kim SK, Melton DA (1998) Notochord repression of endodermal Sonic hedgehog permits pancreas development. Genes Dev 12:1705-1713

27. Gu G, Dubauskaite J, Melton DA (2002) Direct evidence for the pancreatic lineage: NGN3+ cells are islet progenitors and are distinct from duct progenitors. Development 129:2447-2457

28. Herrera PL (2000) Adult insulin- and glucagon-producing cells differentiate from two independent cell lineages. Development 127:2317-2322

29. Kawaguchi Y, Cooper B, Gannon M, Ray M, MacDonald RJ, Wright CV (2002) The role of the transcriptional regulator Ptf1a in converting intestinal to pancreatic progenitors. Nat Genet 32:128-134

30. Rausa F, Samadani U, Ye H et al. (1997) The cut-homeodomain transcriptional activator HNF-6 is coexpressed with its target gene HNF-3 beta in the developing murine liver and pancreas. Dev Biol 192:228-246

31. Sander M, Sussel L, Conners J et al. (2000) Homeobox gene Nkx6.1 lies downstream of Nkx2.2 in the major pathway of beta-cell formation in the pancreas. Development 127:5533-5540

32. Sussel L, Kalamaras J, Hartigan-O'Connor DJ et al. (1998) Mice lacking the homeodomain transcription factor $\mathrm{Nkx} 2.2$ have diabetes due to arrested differentiation of pancreatic beta cells. Development 125:2213-2221

33. Li H, Arber S, Jessell TM, Edlund H (1999) Selective agenesis of the dorsal pancreas in mice lacking homeobox gene Hlxb9. Nat Genet 23:67-70

34. Maestro MA, Boj SF, Luco RF et al. (2003) Hnf6 and Tcf2 (MODY5) are linked in a gene network operating in a precursor cell domain of the embryonic pancreas. Hum Mol Genet 12:3307-3314

35. Bort R, Martinez-Barbera JP, Beddington RS, Zaret KS (2004) Hex homeobox gene-dependent tissue positioning is required for organogenesis of the ventral pancreas. Development 131:797-806

36. Jonsson J, Carlsson L, Edlund T, Edlund H (1994) Insulinpromoter-factor 1 is required for pancreas development in mice. Nature 371:606-609
37. Krapp A, Knofler M, Ledermann B et al. (1998) The bHLH protein PTF1-p48 is essential for the formation of the exocrine and the correct spatial organization of the endocrine pancreas. Genes Dev 12:3752-3763

38. Offield MF, Jetton TL, Labosky PA et al. (1996) PDX-1 is required for pancreatic outgrowth and differentiation of the rostral duodenum. Development 122:983-995

39. Ahlgren U, Pfaff SL, Jessell TM, Edlund T, Edlund H (1997) Independent requirement for ISL1 in formation of pancreatic mesenchyme and islet cells. Nature 385:257260

40. Harrison KA, Thaler J, Pfaff SL, Gu H, Kehrl JH (1999) Pancreas dorsal lobe agenesis and abnormal islets of Langerhans in Hlxb9-deficient mice. Nat Genet 23:71-75

41. Ferber S, Halkin A, Cohen H et al. (2000) Pancreatic and duodenal homeobox gene 1 induces expression of insulin genes in liver and ameliorates streptozotocin-induced hyperglycemia. Nat Med 6:568-572

42. Zalzman M, Gupta S, Giri RK et al. (2003) Reversal of hyperglycemia in mice by using human expandable insulinproducing cells differentiated from fetal liver progenitor cells. Proc Natl Acad Sci USA 100:7253-7258

43. Horb ME, Shen CN, Tosh D, Slack JM (2003) Experimental conversion of liver to pancreas. Curr Biol 13:105-115

44. Stafford D, Prince VE (2002) Retinoic acid signaling is required for a critical early step in zebrafish pancreatic development. Curr Biol 12:1215-1220

45. Jacquemin P, Lemaigre FP, Rousseau GG (2003) The Onecut transcription factor HNF-6 (OC-1) is required for timely specification of the pancreas and acts upstream of Pdx-1 in the specification cascade. Dev Biol 258:105-116

46. Gerrish K, Cissell MA, Stein R (2001) The role of hepatic nuclear factor 1 alpha and PDX-1 in transcriptional regulation of the pdx-1 gene. J Biol Chem 276:47775-47784

47. Marshak S, Benshushan E, Shoshkes M, Havin L, Cerasi E, Melloul D (2000) Functional conservation of regulatory elements in the pdx-1 gene: PDX-1 and hepatocyte nuclear factor 3 beta transcription factors mediate beta-cell-specific expression. Mol Cell Biol 20:7583-7590

48. Wu KL, Gannon M, Peshavaria M et al. (1997) Hepatocyte nuclear factor 3 beta is involved in pancreatic beta-cellspecific transcription of the pdx-1 gene. Mol Cell Biol 17:6002-6013

49. Samaras SE, Cissell MA, Gerrish K, Wright CV, Gannon M, Stein R (2002) Conserved sequences in a tissue-specific regulatory region of the $\mathrm{pdx}-1$ gene mediate transcription in pancreatic beta cells: role for hepatocyte nuclear factor 3 beta and Pax6. Mol Cell Biol 22:4702-4713

50. Gerrish K, Gannon M, Shih D et al. (2000) Pancreatic beta cell-specific transcription of the pdx-1 gene. The role of conserved upstream control regions and their hepatic nuclear factor 3beta sites. J Biol Chem 275:3485-3492

51. Annicotte JS, Fayard E, Swift GH et al. (2003) Pancreaticduodenal homeobox 1 regulates expression of liver receptor homolog 1 during pancreas development. Mol Cell Biol 23:6713-6724

52. Rausa FM, Galarneau L, Belanger L, Costa RH (1999) The nuclear receptor fetoprotein transcription factor is coexpressed with its target gene HNF-3beta in the developing murine liver, intestine and pancreas. Mech Dev 89:185-188

53. Grapin-Botton A, Majithia AR, Melton DA (2001) Key events of pancreas formation are triggered in gut endoderm by ectopic expression of pancreatic regulatory genes. Genes Dev 15:444-454

54. Pictet RL, Clark WR, Williams RH, Rutter WJ (1972) An ultrastructural analysis of the developing embryonic pancreas. Dev Biol 29:436-467 
55. Herrera PL, Huarte J, Sanvito F, Meda P, Orci L, Vassalli JD (1991) Embryogenesis of the murine endocrine pancreas; early expression of pancreatic polypeptide gene. Development 113:1257-1265

56. Gradwohl G, Dierich A, LeMeur M, Guillemot F (2000) Neurogenin3 is required for the development of the four endocrine cell lineages of the pancreas. Proc Natl Acad Sci USA 97:1607-1611

57. Jensen J, Pedersen EE, Galante P et al. (2000) Control of endodermal endocrine development by Hes-1. Nat Genet 24:36-44

58. Lee JC, Smith SB, Watada H et al. (2001) Regulation of the pancreatic pro-endocrine gene neurogenin3. Diabetes 50:928-936

59. Apelqvist A, Li H, Sommer L et al. (1999) Notch signalling controls pancreatic cell differentiation. Nature 400:877-881

60. Hald J, Hjorth JP, German MS, Madsen OD, Serup P, Jensen J (2003) Activated Notch1 prevents differentiation of pancreatic acinar cells and attenuate endocrine development. Dev Biol 260:426-437

61. Murtaugh LC, Stanger BZ, Kwan KM, Melton DA (2003) Notch signaling controls multiple steps of pancreatic differentiation. Proc Natl Acad Sci USA 100:14920 14925

62. Lammert E, Brown J, Melton DA (2000) Notch gene expression during pancreatic organogenesis. Mech Dev 94:199-203

63. Heremans Y, Van De Casteele M, Veld P in't et al. (2002) Recapitulation of embryonic neuroendocrine differentiation in adult human pancreatic duct cells expressing neurogenin 3. J Cell Biol 159:303-312

64. Jensen J, Heller RS, Funder-Nielsen T et al. (2000) Independent development of pancreatic alpha- and beta-cells from neurogenin3-expressing precursors: a role for the notch pathway in repression of premature differentiation. Diabetes 49:163-176

65. Jacquemin P, Durviaux SM, Jensen J et al. (2000) Transcription factor hepatocyte nuclear factor 6 regulates pancreatic endocrine cell differentiation and controls expression of the proendocrine gene ngn3. Mol Cell Biol 20:4445-4454

66. Clotman F, Lannoy VJ, Reber M et al. (2002) The onecut transcription factor HNF6 is required for normal development of the biliary tract. Development 129:1819-1828

67. Coffinier C, Gresh L, Fiette L et al. (2002) Bile system morphogenesis defects and liver dysfunction upon targeted deletion of HNF1beta. Development 129:1829-1838

68. Barbacci E, Reber M, Ott MO, Breillat C, Huetz F, Cereghini S (1999) Variant hepatocyte nuclear factor 1 is required for visceral endoderm specification. Development 126:4795-4805

69. Coffinier C, Thepot D, Babinet C, Yaniv M, Barra J (1999) Essential role for the homeoprotein vHNF1/HNF1beta in visceral endoderm differentiation. Development 126:47854794

70. Gautier JF, Bellanné-Chantelot C, Dubois-Laforgue D et al. (2002) Multi-organ damage in MODY5 related to mutations of the hepatocyte nuclear factor- $1 \mathrm{~b}$ gene. Diabetes 51 [Suppl]:A260 (Abstract)

71. Sumazaki R, Shiojiri N, Isoyama S et al. (2004) Conversion of biliary system to pancreatic tissue in Hes1-deficient mice. Nat Genet 36:83-87

72. Schwitzgebel VM, Scheel DW, Conners JR et al. (2000) Expression of neurogenin3 reveals an islet cell precursor population in the pancreas. Development 127:35333542
73. Naya FJ, Huang HP, Qiu Y et al. (1997) Diabetes, defective pancreatic morphogenesis, and abnormal enteroendocrine differentiation in BETA2/neuroD-deficient mice. Genes Dev 11:2323-2334

74. Smith SB, Gasa R, Watada H, Wang J, Griffen SC, German MS (2003) Neurogenin3 and hepatic nuclear factor 1 cooperate in activating pancreatic expression of Pax4. J Biol Chem 278:38254-38259

75. Sosa-Pineda B, Chowdhury K, Torres M, Oliver G, Gruss P (1997) The Pax4 gene is essential for differentiation of insulin-producing beta cells in the mammalian pancreas. Nature 386:399-402

76. Collombat P, Mansouri A, Hecksher-Sorensen $\mathrm{J}$ et al. (2003) Opposing actions of Arx and Pax4 in endocrine pancreas development. Genes Dev 17:2591-2603

77. Huang HP, Liu M, El Hodiri HM, Chu K, Jamrich M, Tsai MJ (2000) Regulation of the pancreatic islet-specific gene BETA2 (neuroD) by neurogenin 3. Mol Cell Biol 20:3292-3307

78. Watada H, Scheel DW, Leung J, German MS (2003) Distinct gene expression programs function in progenitor and mature islet cells. J Biol Chem 278:17130-17140

79. Smith SB, Watada H, German MS (2004) Neurogenin3 activates the islet differentiation program while repressing its own expression. Mol Endocrinol 18:142-149

80. Bonner-Weir S (2000) Perspective: postnatal pancreatic beta cell growth. Endocrinology 141:1926-1929

81. Rorsman P, Renstrom E (2003) Insulin granule dynamics in pancreatic beta cells. Diabetologia 46:1029-1045

82. Cardozo AK, Heimberg H, Heremans Y et al. (2001) A comprehensive analysis of cytokine-induced and nuclear factor-kappa B-dependent genes in primary rat pancreatic beta-cells. J Biol Chem 276:48879-48886

83. Thomas MK, Devon ON, Lee JH et al. (2001) Development of diabetes mellitus in aging transgenic mice following suppression of pancreatic homeoprotein IDX-1. J Clin Invest 108:319-329

84. Holland AM, Hale MA, Kagami H, Hammer RE, MacDonald RJ (2002) Experimental control of pancreatic development and maintenance. Proc Natl Acad Sci USA 99:12236-12241

85. Wang H, Maechler P, Ritz-Laser B et al. (2001) Pdx1 level defines pancreatic gene expression pattern and cell lineage differentiation. J Biol Chem 276:25279-25286

86. Carty MD, Lillquist JS, Peshavaria M, Stein R, Soeller WC (1997) Identification of cis- and trans-active factors regulating human islet amyloid polypeptide gene expression in pancreatic beta-cells. J Biol Chem 272:11986-11993

87. Serup P, Jensen J, Andersen FG et al. (1996) Induction of insulin and islet amyloid polypeptide production in pancreatic islet glucagonoma cells by insulin promoter factor 1 . Proc Natl Acad Sci USA 93:9015-9020

88. Watada H, Mirmira RG, Leung J, German MS (2000) Transcriptional and translational regulation of beta-cell differentiation factor Nkx6.1. J Biol Chem 275:34224-34230

89. Waeber G, Thompson N, Nicod P, Bonny C (1996) Transcriptional activation of the GLUT2 gene by the IPF-1/ STF-1/IDX-1 homeobox factor. Mol Endocrinol 10:13271334

90. Chakrabarti SK, James JC, Mirmira RG (2002) Quantitative assessment of gene targeting in vitro and in vivo by the pancreatic transcription factor, Pdx1. Importance of chromatin structure in directing promoter binding. J Biol Chem 277:13286-13293

91. Cissell MA, Zhao L, Sussel L, Henderson E, Stein R (2003) Transcription factor occupancy of the insulin gene in vivo. Evidence for direct regulation by $\mathrm{Nkx} 2.2$. J Biol Chem 278:751-756 
92. Brissova M, Shiota M, Nicholson WE et al. (2002) Reduction in pancreatic transcription factor PDX-1 impairs glucose-stimulated insulin secretion. J Biol Chem 277:11225-11232

93. Shih DQ, Heimesaat M, Kuwajima S, Stein R, Wright CV, Stoffel M (2002) Profound defects in pancreatic beta-cell function in mice with combined heterozygous mutations in Pdx-1, Hnf-1alpha, and Hnf-3beta. Proc Natl Acad Sci USA 99:3818-3823

94. Johnson JD, Ahmed NT, Luciani DS et al. (2003) Increased islet apoptosis in $\mathrm{Pdx} 1+/-$ mice. J Clin Invest 111:1147-1160

95. Stoffers DA, Ferrer J, Clarke WL, Habener JF (1997) Early-onset type-II diabetes mellitus (MODY4) linked to IPF1. Nat Genet 17:138-139

96. Melloul D, Marshak S, Cerasi E (2002) Regulation of pdx-1 gene expression. Diabetes 51 [Suppl]:S320-S325

97. Sharma S, Jhala US, Johnson T, Ferreri K, Leonard J, Montminy M (1997) Hormonal regulation of an isletspecific enhancer in the pancreatic homeobox gene STF-1. Mol Cell Biol 17:2598-2604

98. Ben-Shushan E, Marshak S, Shoshkes M, Cerasi E, Melloul D (2001) A pancreatic beta -cell-specific enhancer in the human PDX-1 gene is regulated by hepatocyte nuclear factor 3 beta (HNF-3beta ), HNF-1alpha, and SPs transcription factors. J Biol Chem 276:1753317540

99. Lee CS, Sund NJ, Vatamaniuk MZ, Matschinsky FM, Stoffers DA, Kaestner KH (2002) Foxa2 controls Pdx1 gene expression in pancreatic beta-cells in vivo. Diabetes $51: 2546-2551$

100. Samaras SE, Zhao L, Means A, Henderson E, Matsuoka TA, Stein R (2003) The islet beta cell-enriched RIPE3b1/Maf transcription factor regulates pdx-1 expression. J Biol Chem 278:12263-12270

101. Nammo T, Yamagata K, Hamaoka R et al. (2002) Expression profile of MODY3/HNF-1alpha protein in the developing mouse pancreas. Diabetologia 45:11421153

102. Wang H, Maechler P, Hagenfeldt KA, Wollheim CB (1998) Dominant-negative suppression of HNF-1alpha function results in defective insulin gene transcription and impaired metabolism-secretion coupling in a pancreatic beta-cell line. EMBO J 17:6701-6713

103. White MF (2002) IRS proteins and the common path to diabetes. Am J Physiol Endocrinol Metab 283:E413E422

104. Kitamura T, Nakae J, Kitamura Y et al. (2002) The forkhead transcription factor Foxo1 links insulin signaling to $\mathrm{Pdx} 1$ regulation of pancreatic beta cell growth. J Clin Invest 110:1839-1847

105. Kushner JA, Ye J, Schubert M et al. (2002) Pdx1 restores beta cell function in Irs2 knockout mice. J Clin Invest 109:1193-1201

106. Nakae J, Biggs WH 3rd, Kitamura T et al. (2002) Regulation of insulin action and pancreatic beta-cell function by mutated alleles of the gene encoding forkhead transcription factor Foxo1. Nat Genet 32:245-253

107. Kulkarni RN, Bruning JC, Winnay JN, Postic C, Magnuson MA, Kahn CR (1999) Tissue-specific knockout of the insulin receptor in pancreatic beta cells creates an insulin secretory defect similar to that in type 2 diabetes. Cell 96:329-339

108. Kulkarni RN, Holzenberger M, Shih DQ et al. (2002) Beta-cell-specific deletion of the Igf1 receptor leads to hyperinsulinemia and glucose intolerance but does not alter beta-cell mass. Nat Genet 31:111-115
109. Kido Y, Nakae J, Hribal ML, Xuan S, Efstratiadis A, Accili D (2002) Effects of mutations in the insulin-like growth factor signaling system on embryonic pancreas development and beta-cell compensation to insulin resistance. J Biol Chem 277:36740-36747

110. Xuan S, Kitamura T, Nakae J et al. (2002) Defective insulin secretion in pancreatic beta cells lacking type 1 IGF receptor. J Clin Invest 110:1011-1019

111. Melloul D, Marshak S, Cerasi E (2002) Regulation of insulin gene transcription. Diabetologia 45:309326

112. German M, Ashcroft S, Docherty K et al. (1995) The insulin gene promoter. A simplified nomenclature. Diabetes 44:1002-1004

113. Ohlsson H, Karlsson K, Edlund T (1993) IPF1, a homeodomain-containing transactivator of the insulin gene. EMBO J 12:4251-4259

114. Olbrot M, Rud J, Moss LG, Sharma A (2002) Identification of beta-cell-specific insulin gene transcription factor RIPE3b1 as mammalian MafA. Proc Natl Acad Sci USA 99:6737-6742

115. Matsuoka TA, Zhao L, Artner I et al. (2003) Members of the large Maf transcription family regulate insulin gene transcription in islet beta cells. Mol Cell Biol 23:6049-6062

116. Naya FJ, Stellrecht CM, Tsai MJ (1995) Tissue-specific regulation of the insulin gene by a novel basic helix-loop-helix transcription factor. Genes Dev 9:1009-1019

117. Miller CP, McGehee RE Jr, Habener JF (1994) IDX-1: a new homeodomain transcription factor expressed in rat pancreatic islets and duodenum that transactivates the somatostatin gene. EMBO J 13:1145-1156

118. Leonard J, Peers B, Johnson T, Ferreri K, Lee S, Montminy MR (1993) Characterization of somatostatin transactivating factor-1, a novel homeobox factor that stimulates somatostatin expression in pancreatic islet cells. Mol Endocrinol 7:1275-1283

119. Marshak S, Totary H, Cerasi E, Melloul D (1996) Purification of the beta-cell glucose-sensitive factor that transactivates the insulin gene differentially in normal and transformed islet cells. Proc Natl Acad Sci USA 93:15057-15062

120. Kataoka K, Han SI, Shioda S, Hirai M, Nishizawa M, Handa H (2002) MafA is a glucose-regulated and pancreatic beta-cell-specific transcriptional activator for the insulin gene. J Biol Chem 277:49903-49910

121. Lee JE, Hollenberg SM, Snider L, Turner DL, Lipnick N, Weintraub H (1995) Conversion of Xenopus ectoderm into neurons by NeuroD, a basic helix-loop-helix protein. Science 268:836-844

122. Stellrecht CM, DeMayo FJ, Finegold MJ, Tsai MJ (1997) Tissue-specific and developmental regulation of the rat insulin II gene enhancer, RIPE3, in transgenic mice. J Biol Chem 272:3567-3572

123. Glick E, Leshkowitz D, Walker MD (2000) Transcription factor BETA2 acts cooperatively with E2A and PDX1 to activate the insulin gene promoter. $\mathrm{J}$ Biol Chem 275:2199-2204

124. Malecki MT, Jhala US, Antonellis A et al. (1999) Mutations in NEUROD1 are associated with the development of type 2 diabetes mellitus. Nat Genet 23:323328

125. Qiu Y, Guo M, Huang S, Stein R (2002) Insulin gene transcription is mediated by interactions between the p300 coactivator and PDX-1, BETA2, and E47. Mol Cell Biol 22:412-420 
126. Sander M, Neubuser A, Kalamaras J, Ee HC, Martin GR, German MS (1997) Genetic analysis reveals that PAX6 is required for normal transcription of pancreatic hormone genes and islet development. Genes Dev 11:16621673

127. Moates JM, Nanda S, Cissell MA, Tsai MJ, Stein R (2003) BETA2 activates transcription from the upstream glucokinase gene promoter in islet beta-cells and gut endocrine cells. Diabetes 52:403-408

128. Lee TI, Rinaldi NJ, Robert F et al. (2002) Transcriptional regulatory networks in Saccharomyces cerevisiae. Science 298:799-804

129. Shen-Orr SS, Milo R, Mangan S, Alon U (2002) Network motifs in the transcriptional regulation network of Escherichia coli. Nat Genet 31:64-68

130. Milo R, Shen-Orr S, Itzkovitz S, Kashtan N, Chklovskii D, Alon U (2002) Network motifs: simple building blocks of complex networks. Science 298:824-827

131. Mangan S, Alon U (2003) Structure and function of the feed-forward loop network motif. Proc Natl Acad Sci USA 100:11980-11985

132. Horikawa Y, Iwasaki N, Hara M et al. (1997) Mutation in hepatocyte nuclear factor-1 beta gene (TCF2) associated with MODY. Nat Genet 17:384-385

133. Yamagata K, Oda N, Kaisaki PJ et al. (1996) Mutations in the hepatocyte nuclear factor-1alpha gene in maturityonset diabetes of the young (MODY3). Nature 384:455458

134. Yamagata K, Furuta H, Oda N et al. (1996) Mutations in the hepatocyte nuclear factor-4alpha gene in maturityonset diabetes of the young (MODY1). Nature 384:458460

135. Froguel P, Vaxillaire M, Sun F et al. (1992) Close linkage of glucokinase locus on chromosome $7 p$ to early-onset non-insulin-dependent diabetes mellitus. Nature 356:162164

136. Stoffel M, Duncan SA (1997) The maturity-onset diabetes of the young (MODY1) transcription factor HNF4alpha regulates expression of genes required for glucose transport and metabolism. Proc Natl Acad Sci USA 94:13209-13214

137. Vaxillaire M, Abderrahmani A, Boutin P et al. (1999) Anatomy of a homeoprotein revealed by the analysis of human MODY3 mutations. J Biol Chem 274:35639_ 35646

138. Hansen SK, Parrizas M, Jensen ML et al. (2002) Genetic evidence that HNF-1alpha-dependent transcriptional control of HNF-4alpha is essential for human pancreatic beta cell function. J Clin Invest 110:827833

139. Thomas H, Badenberg B, Bulman M et al. (2002) Evidence for haploinsufficiency of the human HNF1alpha gene revealed by functional characterization of MODY3associated mutations. Biol Chem 383:1691-1700

140. Gragnoli C, Lindner T, Cockburn BN et al. (1997) Maturity-onset diabetes of the young due to a mutation in the hepatocyte nuclear factor-4 alpha binding site in the promoter of the hepatocyte nuclear factor-1 alpha gene. Diabetes 46:1648-1651

141. Byrne MM, Sturis J, Fajans SS et al. (1995) Altered insulin secretory responses to glucose in subjects with a mutation in the MODY1 gene on chromosome 20. Diabetes 44:699-704

142. Lehto M, Tuomi T, Mahtani MM et al. (1997) Characterization of the MODY3 phenotype. Early-onset diabetes caused by an insulin secretion defect. J Clin Invest 99:582-591
143. Frayling TM, Evans JC, Bulman MP et al. (2001) Betacell genes and diabetes: molecular and clinical characterization of mutations in transcription factors. Diabetes 50 [Suppl]:S94-S100

144. Pearson ER, Starkey BJ, Powell RJ, Gribble FM, Clark PM, Hattersley AT (2003) Genetic cause of hyperglycaemia and response to treatment in diabetes. Lancet 362:1275-1281

145. Lee YH, Sauer B, Gonzalez FJ (1998) Laron dwarfism and non-insulin-dependent diabetes mellitus in the Hnf1alpha knockout mouse. Mol Cell Biol 18:3059-3068

146. Pontoglio M, Sreenan S, Roe M et al. (1998) Defective insulin secretion in hepatocyte nuclear factor 1alpha-deficient mice. J Clin Invest 101:2215-2222

147. Dukes ID, Sreenan S, Roe MW et al. (1998) Defective pancreatic beta-cell glycolytic signaling in hepatocyte nuclear factor-1alpha-deficient mice. J Biol Chem 273:24457-24464

148. Wang H, Antinozzi PA, Hagenfeldt KA, Maechler P, Wollheim CB (2000) Molecular targets of a human HNF1 alpha mutation responsible for pancreatic beta-cell dysfunction. EMBO J 19:4257-4264

149. Thomas H, Jaschkowitz K, Bulman M et al. (2001) A distant upstream promoter of the HNF-4alpha gene connects the transcription factors involved in maturity-onset diabetes of the young. Hum Mol Genet 10:2089-2097

150. Jiang S, Tanaka T, Iwanari $\mathrm{H}$ et al. (2003) Expression and localization of $\mathrm{P} 1$ promoter-driven hepatocyte nuclear factor-4alpha (HNF4alpha) isoforms in human and rats. Nucl Recept 1:5

151. Gloyn AL, Ellard S, Shepherd M et al. (2002) Maturityonset diabetes of the young caused by a balanced translocation where the $20 \mathrm{q} 12$ break point results in disruption upstream of the coding region of hepatocyte nuclear factor-4alpha (HNF4A) gene. Diabetes 51:2329-2333

152. Eeckhoute J, Moerman E, Bouckenooghe T et al. (2003) Hepatocyte nuclear factor 4 alpha isoforms originated from the P1 promoter are expressed in human pancreatic beta-cells and exhibit stronger transcriptional potentials than P2 promoter-driven isoforms. Endocrinology 144:1686-1694

153. Chen WS, Manova K, Weinstein DC et al. (1994) Disruption of the HNF-4 gene, expressed in visceral endoderm, leads to cell death in embryonic ectoderm and impaired gastrulation of mouse embryos. Genes Dev 8:2466-2477

154. Li J, Ning G, Duncan SA (2000) Mammalian hepatocyte differentiation requires the transcription factor HNF4alpha. Genes Dev 14:464-474

155. Tian JM, Schibler U (1991) Tissue-specific expression of the gene encoding hepatocyte nuclear factor 1 may involve hepatocyte nuclear factor 4. Genes Dev 5:22252234

156. Kuo CJ, Conley PB, Chen L, Sladek FM, Darnell JE Jr, Crabtree GR (1992) A transcriptional hierarchy involved in mammalian cell-type specification. Nature 355:457-461

157. Hayhurst GP, Lee YH, Lambert G, Ward JM, Gonzalez FJ (2001) Hepatocyte nuclear factor 4alpha (nuclear receptor 2A1) is essential for maintenance of hepatic gene expression and lipid homeostasis. Mol Cell Biol 21:1393-1403

158. Shih DQ, Bussen M, Sehayek E et al. (2001) Hepatocyte nuclear factor-1alpha is an essential regulator of bile acid and plasma cholesterol metabolism. Nat Genet 27:375382

159. Laurent M, Kellershohn N (1999) Multistability: a major means of differentiation and evolution in biological systems. Trends Biochem Sci 24:418-422 
160. Xiong W, Ferrell JE Jr (2003) A positive-feedback-based bistable 'memory module' that governs a cell fate decision. Nature 426:460-465

161. Cook DL, Gerber AN, Tapscott SJ (1998) Modeling stochastic gene expression: implications for haploinsufficiency. Proc Natl Acad Sci USA 95:15641-15646

162. Blake WJ, Kaern M, Cantor CR, Collins JJ (2003) Noise in eukaryotic gene expression. Nature 422:633-637

163. Wang W, Cherry JM, Botstein D, Li H (2002) A systematic approach to reconstructing transcription networks in Saccharomyces cerevisiae. Proc Natl Acad Sci USA 99:16893-16898

164. Albert R, Jeong H, Barabasi AL (2000) Error and attack tolerance of complex networks. Nature 406:378-382
165. Jeong H, Tombor B, Albert R, Oltvai ZN, Barabasi AL (2000) The large-scale organization of metabolic networks. Nature 407:651-654

166. Rao CV, Arkin AP (2001) Control motifs for intracellular regulatory networks. Annu Rev Biomed Eng 3:391-419

167. Parrizas M, Boj SF, Luco RF, Maestro MA, Ferrer J (2003) Chromatin immunoprecipitation using isolated islets of Langerhans. Methods Mol Med 83:61-71

168. Ren B, Robert F, Wyrick JJ et al. (2000) Genome-wide location and function of DNA binding proteins. Science 290:2306-2309

169. Simon I, Barnett J, Hannett N et al. (2001) Serial regulation of transcriptional regulators in the yeast cell cycle. Cell 106:697-708 